\section{Elinital department.}

\section{CUMULATIVE CONSTIPATION.}

BY HKN IR M. FILLD, M.1), NEWTON, I'rofessor of Therapeutics in the Dartmouth Medical School.

'I'HE fact that during the brief ten days since I returned from my annual course of lectures at Dartmouth College, I have encountered two cases of cumulative constipation, - one a very pronounced case, un. der the attendunce of a competent physician, and seen by myself in consultation, - affords the motif of a brief paper, which perhaps you will kindly accept and insert in your columns.

I say recent experience suggests this communication; but $I$ have long been satisfied that the general profession knew relatively but little concerning the subject of my paper.

I intend, as from necessity, to keep well read up in practical therapeutics; and when the Blakistons published my book upon "Cathartics and Emetics," in 1887 , - wherein, in its proper place, cumulative constipation, is discussed, - I was well assured (and I have received no evidence contrawise since then) that myself was the first writer who had given especial attention to this subject; at least, so far as writings in Fnglish, French and German are concerned.

A special study of this most ancomfortable condition, for more than ten years past, has increasingly impressed me with the fact of a kind of treacherous obscurity which appears to be inherent to it. 'That is to say in one sentence : It is not individuals of irregular lives, the ignorant, the indifferent as concerns the essential conditions of health, who are chiefly the subjects of the affection under discussion; and, again, failure in recognition as to the patient's real state, false diagnosis, has quite as often as otherwise fallen to the lot of the careful and competent physician.

In the interest of brevity - and without illustrations drawn from clinical experience, which would expand my promised brief paper to the dimensions of a brochure - I will say that cumulative constipation presents generically two typical forms; namely, that attended with diarrhoea and the form without such complication.

'The physiological experiments of Brunton are familiar to all; by which it was shown that a gentle tickling of the intestine with a feather would occasion a considerable secretion of mucus with a subsequent downward passage of such mucus. Now the representative patient, whom we have so often seen, will, quite likely insist that he has been regular every day, surely for the last two or three weeks; but quite as often as otherwise has not observed that the usual daily evacuation was not an evacuation. 'The force of habit has prevailed to the extent of procuring regularly diurnal defecation; but, day after day, one-half or one-third of the facal quantity which should have been discharged, was retained. 'Thus, progressingly, the large intestine and, later, the small intestine got packed; until at a certain epoch the imbecile vis medicatrix nature offers its aid. Imbecile, because the secretion, which the irritating fæcal mass has provoked, as in the irritation of Brunton's feather experiment, is poured out at the locus (or below) of the cumulation packing : it cun avail nothing in dislodying the "facal plug," as it might have uvailed if only the glandular outflow had been brought to bear a little higher up.
After a period of such diarrhœa, with anorexia, the patient seeks medical advice, and he will be exceptionally fortunate if the doctor does not prescribe opiates and astringents. I remember the case of a young lady, seen several years ago, exactly representing this condition; her physician had given his diagnosis - "typhoid fever" - I whispered in his ear. after our consultation, "we will cure this typhoid fever within twenty-four hours"; and results verified the promise made.

'The second variety of cumulative constipation is the affection under liscussion but uncomplicated with diarrhoea, and it is wonderful to observe how "regular" and cleanly a person may be and yet this long. continued daily incomplete defecation, and to remark what an immense amount of facal matter the bowels may be induced to pack away; this often, without any serious danger to health and with but temporary inconvenience.

What is the treatment? It may well be that the advent of the doctor has close association with the tirst approach of danger to the sufferer. What information do our standard text-books give us - whether books devoted to therapeutics or to practice - as to the selection of cathartic materials, in an emergency like this! In a word, our treatment must be progressive and cumulative as has been the condition against which it is directed, and, first, to state it negatively, avoid senna and all like convulsivant cathartics, un. less you would expose the patient to the tortures of colic in its worst form. 'To give a saline, in whatever form or quantity, is little better than to give "an inverted injection"; moreover, there must be an element of peristaltic power beyoud what salines possess, and, finally, in the preseut state, great drenches would be required, forced upon the man who is already more than full, and, to make one more negative point, all cathartics must be avoided which act so high up on the intestinal tract, as, possibly, to involve the stomach in their irritation; vomiting is always more or less im. minent in the subject of cumulative constipation, and, if gastric continence be lost early in the treatment of the case, the condition has become serious indeed.

And now for a brief positive statement as to treatment. 'The patient will pretty surely be an adult; have him kept quiet in bed, watch the stomach and order every hour one compound rhubarb pill. The prescription should call for twenty such pills, they should be freshly made and, if nausea threatens, each pill may be lightly coated with silver leaf. Let the patient understand that he will probably require as many as fifteen of these pills before the bowels give evidence of response. Indeed, in the case lately seen in consultation, twenty pills were swallowed - one every hour - and still further help was demanded by means of the fountain syringe and rectal bougie, used by the attending physicians.

The treatment, thus sketched, rarely fails; and when the bowels begin to unload, little or no pain attends the process, although great surprise may be expressed at the quantities of long-stored facal matter discharged.

- Hospital-ity. - Hospital physician (with a view to diagnosis): "What do you drink?" - New patient (cheering up at the proposal): "Oh, sir! - thank you, sir-whatever you - I leave that to you, sir!"London Punch. 